\title{
The diagnosis of non-small cell lung cancer in the molecular era
}

\author{
Jennifer Brainard ${ }^{1} \cdot$ Carol Farver $^{1}$
}

Received: 20 August 2018 / Accepted: 20 August 2018 / Published online: 2 January 2019

(c) United States \& Canadian Academy of Pathology 2019

\begin{abstract}
Lung carcinoma is the leading cause of cancer mortality for both genders in the United States and throughout the world. Many of these tumors are being diagnosed with minimally invasive means resulting in small samples. There is a need to extract an increasing amount of therapeutic and prognostic information from progressively smaller samples. Collaboration among clinicians and pathologists is needed to produce a comprehensive final diagnosis in patients with lung cancer. This collaboration facilitates triage of small samples for ancillary studies including molecular testing. What follows represents a review of the current required testing for lung cancer specimens, an example of an algorithm currently employed at the Cleveland Clinic so that all required tests can be performed even on the smallest of specimens and suggestions on how pathologists may approach this new era of "doing more with less".
\end{abstract}

\section{Introduction}

Lung cancer is the leading cause of cancer deaths throughout the world, accounting for approximately $25 \%$ of all cancer deaths or approximately 1.5 million deaths annually [1, 2]. In the United States, $28 \%$ of cancer deaths in men and $26 \%$ of cancer deaths in women are due to lung cancer, with 158,000 Americans dying from lung cancer in 2016 [2]. Lung cancer also has among the worst 5 -year survivals of any cancer at $17.7 \%$ [2] and over the past 50 years, little progress has been made in improving this. This poor prognosis is a result of the late stage at which most lung cancers present. Current data reveal that $57 \%$ of lung cancers present with clinical stage IV disease that has less than an $8 \%$ survival rate [1]. The overall poor survival of advanced-stage lung cancer patients is due to two factors. First, lung cancer, unlike other cancers such as prostate, cervical or colorectal, does not have an effective screening test to find early-stage disease. Recently, low-dose high-resolution chest computed tomography (CT) has been shown to be effective in picking up early, curable disease and may decrease the

\section{Jennifer Brainard}

brainaj@ccf.org

1 Department of Pathology, Cleveland Clinic, Cleveland, OH, USA amount of late-stage disease seen at the initial presentation [3]. The second factor is the relative ineffectiveness of systemic therapies as current data demonstrate no survival benefit from chemotherapy and/or radiotherapy in these patients [4].

Over the past 10 years, genomic studies of non-small cell lung cancer have discovered molecular activating mutations, particularly in lung adenocarcinomas, that have led to molecular therapies that target specific mutations and have provided significant survival benefit for some patients with advanced lung cancer [5]. However, these studies found a difference in adenocarcinomas versus squamous cell carcinomas in the type of targetable mutations and, thus, molecular therapies used. From this, grew the need to differentiate non-small cell lung cancer (NSCLC) into specific cell types for therapeutic reasons and to provide guidelines from the pathology community regarding how and when to perform these tests on the tissue procured for diagnosis. In this new molecular era of lung cancer therapies, the testing menu on these specimens has greatly expanded and the expectation now by clinicians and patients alike is that these tests are performed on all valid specimens, despite the size of the tissue. What follows represents a review of the current required testing for lung cancer specimens, an example of an algorithm currently employed at the Cleveland Clinic so that all required tests can be performed even on the smallest of specimens and suggestions on how pathologists may approach this new era of "doing more with less". 


\section{The pathological diagnosis of lung cancer in the molecular era}

Prior to the discovery of molecular targetable therapies, the pathologist's diagnosis of lung cancer was a simple binary choice: NSCLC and small cell lung cancer (SCLC). In 2004, the discovery of targetable mutations for epidermal growth factor receptor (EGFR) [6-8] and later the identification of the transforming EML4-ALK fusion gene $[9,10]$ changed the pathologist's approach to the diagnosis of NSCLC, necessitating differentiation among the cell types [11] (Fig. 1). With this, several practical guidelines were published to standardize EGFR and $A L K$ testing. These recommendations included: (1) criteria for patients who should be tested, (2) when this testing should be performed, (3) laboratory quality guidelines for the tests and (4) turnaround times for reporting of the results [12-14]. An updated version of these guidelines published in 2017 recommended testing in the following scenarios: (1) patients with advanced-stage disease at the time of diagnosis or in patients with progression who originally presented with a lower-stage disease and were not tested, (2) irrespective of clinical characteristics or when adenocarcinoma cannot be excluded and (3) in tumors with histologies other than adenocarcinoma when clinical features indicate high probability of an oncogenic driver [5, 15, 16]. From this, four areas of inquiry emerged that focused on four practical questions. (1) Can small biopsies be used to accurately determine the cell type of NSCLC? (2) What antibodies accurately diagnose the cell type of NSCLC while optimizing the efficient use of the procured tissue? (3) Does the pathologic screening using these antibodies find all of the tumors with targetable mutations? (4) How does the pathologist best triage these small specimens to accomplish all of the required testing?

First, over the past 10 years there have been a number of studies that have evaluated the question of the accuracy of the tumor diagnosis in small biopsies. In an analysis of those publications, Zachara-Szczakowskii et al. [17] reported that in studies with biopsy and resection specimens $(n=$ 239) using an immunohistochemical panel of thyroid transcription factor-1 (TTF-1), napsin A, p63, p40, cytokeratin$5 / 6(\mathrm{CK} 5 / 6)$ and CK7, there is an overall accuracy of $91 \%$. The major causes for discrepancies as reported in the original studies include evidence of tumor heterogeneity on the resection specimen including evidence for morphologic features of other tumor types that include glandular differentiation in adenocarcinomas and spindle cell or giant cell features in pleomorphic carcinoma. A minor cause for discrepant results was the variation in tissue fixation causing variable antibody staining on biopsies versus resection. However, overall, the data show that small biopsies can accurately predict the tumor type with $>90 \%$ accuracy and allow for subclassification of the tumor even in poorly differentiated tumor histology [17-19].

The second question regarding the most useful and efficient antibody panel was originally posed by Travis et al. [20] in 2011 in the original publication of the International multidisciplinary classification of lung adenocarcinomas. In this was a proposal that one antibody for adenocarcinoma, one antibody for squamous cell carcinoma and one mucin stain should be the ultimate goal for a definitive identification of tumor type [20]. This approach was suggested even in the setting of $30 \%$ of the tumors where relying on histology alone is unhelpful and subtyping is not feasible. With this, studies emerged to define the sensitivities and specificities of the panel of antibodies commonly used to define the cell type in NSCLC with the hope of discouraging the use of less specific testing and to minimize the impact of false positive and negative results while enhancing the accuracy of the morphologic diagnosis. In general, this panel includes TTF-1 and napsin A for adenocarcinomas (Table 1) and p40 and p63 for squamous cell carcinomas (Table 2). The increased sensitivity of TTF-1 over napsin A for lung adenocarcinomas and the increased specificity of p40 over p63 for squamous cell carcinomas led to the conclusion that TTF- 1 for adenocarcinomas and $\mathrm{p} 40$ for squamous cell carcinomas are the most reasonable and reliable antibody panels $[18,21]$. Further, given that the specificity, negative predictive value, positive predictive value and diagnostic accuracy of p40 for squamous cell carcinoma is higher than the corresponding values of TTF-1 for adenocarcinoma, this raises the possibility that in the setting of even very limited tissue (i.e., one antibody test only can be performed), the choice of p40 to rule out squamous differentiation is the most useful tool that one has [21] (Table 3).

The question of the efficacy of the current antibody panels as a screening tool for tumors with targetable mutations has not been well studied. A single retrospective study published in 2015 attempts to answer this question. The authors reviewed all NSCLCs resected at their institution between 2004 and 2010 that were tested for mutations. Of 816 tumors with mutational testing, 336 had mutations and of these, $70 \%$ were KRAS mutations and $30 \%$ were EGFR mutations. Of the tumors with mutations, 5 were squamous cell carcinomas using the current day panel of TTF-1, p40 and a Periodic acid-Schiffs with diastase (PASD) for mucin. The authors found that of the 5 squamous cell carcinomas with mutations, 3 were KRAS mutations without available targetable mutations, and of the 2 EGFR mutations only 1 was targetable. Said another way, $0.12 \%$ of tumors were missed using this screening algorithm $[22,23]$. Though the data available are limited,this suggests that the number of missed targetable mutations using the current antibody panel is exceedingly low. Nonetheless, the 
Fig. 1 a Non-small cell lung carcinoma (NSCLC), formerly considered as a single disease regarding treatment options, must now be accurately cell typed to squamous cell carcinoma (SCC),

adenocarcinoma. b The targetable mutations in adenocarcinoma and squamous cell carcinoma that changed the pathologists' approach to the diagnosis of NSCLC (derived with permission from Hirsch et al. [11])

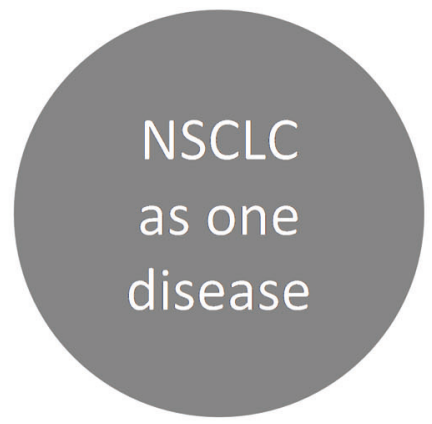

\section{Histology-based Subtyping}
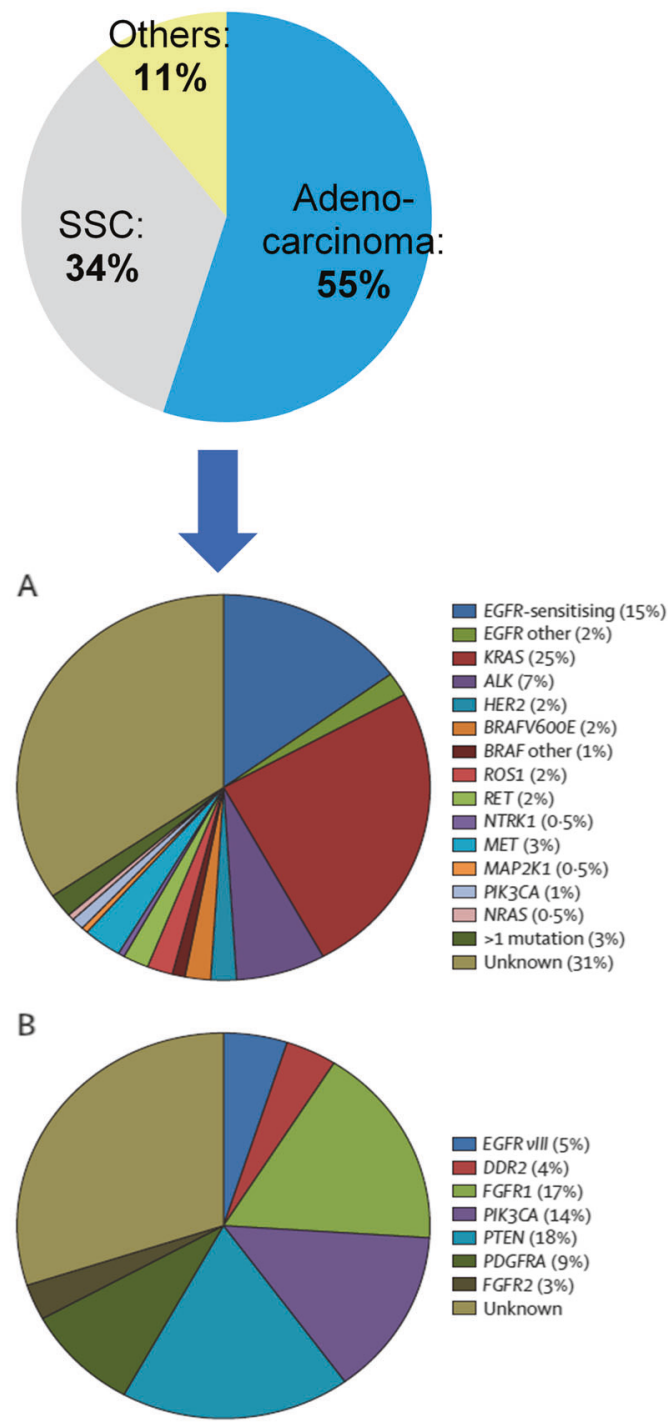

current guidelines offer flexibility for the clinician to request testing in the setting where clinical judgment suggests the patient with a diagnosed squamous cell carcinoma may have targetable mutations and benefit from these molecular therapies. These scenarios include the following: (1) adenosquamous cell carcinoma should be tested given that 
Table 1 Antibodies for adenocarcinoma of the lung

\begin{tabular}{ll}
\hline TTF-1 & Napsin A \\
\hline -Sensitive & •Not as sensitive as TTF-1 \\
•Specific & •Monoclonal is more specific \\
- Ventana 8G7G3/1 & -Cytoplasmic antibody \\
•Non-specific clones & -Labels type 2 pneumocytes and intra-alveolar macrophages \\
- SPT24 & -Is not positive in high-grade neuroendocrine carcinomas such as large cell \\
- SP141 & neuroendocrine carcinomas \\
•Nuclear antibody & \\
-Labels type 2 pneumocytes & \\
\hline
\end{tabular}

See Pelosi et al. [21]

Table 2 Antibodies for squamous cell carcinoma

\begin{tabular}{ll}
\hline p63 & p40 \\
\hline -Very sensitive & •Monoclonal is more sensitive \\
- Less specific & • BIOCARE/ACI3066A \\
- Nuclear antibody & (Mouse monoclonal) \\
- Also found in other tumors & •Very sensitive \\
- Sarcomatoid carcinomas & •Very specific \\
- Large cell carcinomas & - If p40 is negative, it is not \\
- High-grade NE carcinomas & squamous cell \\
- Adenocarcinomas (weakly) & •Nuclear antibody \\
- Adenosquamous cell carcinomas & \\
\hline
\end{tabular}

See Pelosi et al. [21]

Table 3 Negative and positive predictive values of antibodies used in non-small cell lung cancer

\begin{tabular}{lll}
\hline & TTF-1 & p40 \\
\hline Negative predictive value (NPV) & $62-81 \%$ & $100 \%$ \\
Positive predictive value (PPV) & $89-100 \%$ & $90-94 \%$ \\
\hline
\end{tabular}

genomic profiling shows more association of adenosquamous carcinoma with adenocarcinoma; and (2) in small biopsies of non-smokers or light smokers, since misrepresented sampling of squamous cell carcinoma may be a factor [24, 25].

Finally, the important question of how this testing is possible in small specimens remains. Pathology laboratory systems have struggled to develop algorithms that provide the required testing for all pathology specimens regardless of the amount of tissue provided to the laboratory. Early on, adequacy rates for many of these tests were quite low and required innovative approaches for both the initial screening of the tumor tissue for cell type and for subsequent testing of that tissue for targetable mutations. As in many institutions, the Cleveland Clinic Pathology and Laboratory Medicine Institute worked on solutions to this problem through integration of algorithms that combined the pathology specimens procured for cytopathology with those obtained for surgical pathology. In general, screening for cell type using immunohistochemistry focuses on the use of the formalin-fixed, paraffin-embedded surgical pathology

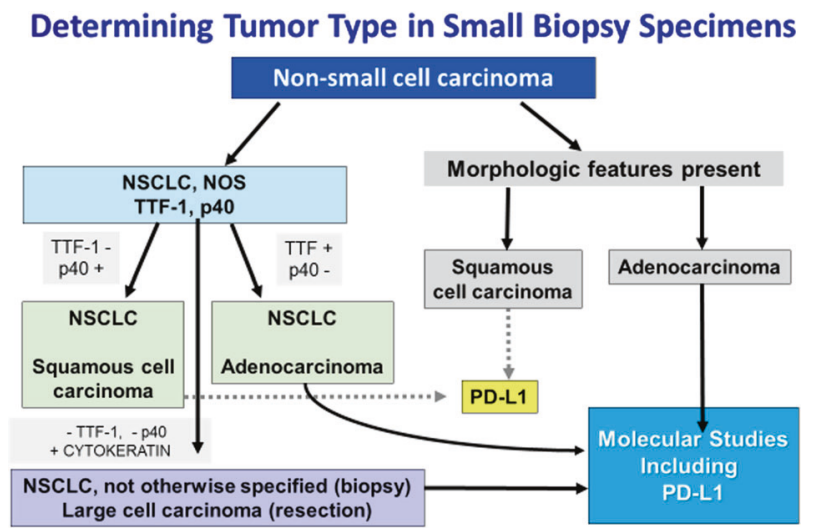

Fig. 2 Algorithm for antibodies employed by the Cleveland Clinic to direct the appropriate molecular testing on biopsy lung cancer specimens

specimens where the antibody testing has been optimized. The initial screening for cell type done on the surgical pathology biopsies uses an algorithm of the common antibodies previously discussed that is performed (see Fig. 2) and these results direct the molecular testing on the cytopathology specimens. The molecular testing, in general, is performed on the cytopathology specimens where processing of complementary DNA (cDNA) and specialized cell preparations, developed to optimize yield and sensitivity for the molecular technologies, are used as described in detail below (Table 4).

Achieving an adequate specimen for molecular testing in lung cancer begins with the sampling procedure itself. Selecting the appropriate diagnostic procedure (bronchoscopic versus CT-guided sampling) for a patient with a lung nodule is the first step and requires a multidisciplinary approach. At our institution, most lung nodules are sampled through the bronchoscope which allows for both diagnosis and staging in a single setting (Table 5). Advanced bronchoscopy at the Cleveland Clinic is

\section{The use of cytopathology specimens for molecular testing}


Table 4 Tissue use for immunohistochemistry and molecular testing Immunohistochemistry for tumor cell cDNA and cell preparations type for molecular testing

- Bronchoscopic biopsy

- Needle core biopsy

- Cell block

- Cell block (formalin-fixed)

- Fine needle aspiration biopsy (methanol-based)

- Bronchoscopic biopsy

- cDNA for EGFR (NGS)

- Needle core biopsy

- cDNA for EGFR (NGS)

- FNAB cell pellet and supernatant

- cDNA for EGFR (NGS)

- FISH for EMLA-ALK

Table 5 Lymph node sampling

EBUS staging

Average number of nodes evaluated per case

Average number of nodes sampled per case

3.45

Average size of nodes sampled per case

$8.45 \mathrm{~mm}$

performed by interventional pulmonologists using endobronchial ultrasound-guidance (EBUS) as well as electromagnetic navigation techniques. Interventional pulmonologists have completed 12 months of subspecialty training in minimally invasive diagnostic and therapeutic pulmonary procedures after completing an accredited pulmonary or pulmonary/critical care fellowship [26]. As a result, they are particularly skilled at obtaining diagnostic material. At our institution, interventional bronchoscopy procedures are largely centralized with the majority performed at two sites in our hospital system, including our Main Campus location. General anesthesia is used for all patients. Cytopathology is in attendance to provide rapid on-site evaluation (ROSE) in all cases. For patients with a non-small cell carcinoma at ROSE, 6-7 total passes from the diagnostic site are obtained. Multiple passes, generally at least three per site, with lymphoid tissue are obtained from benign lymph node stations.

ROSE increases the value of the sampling procedure for patients [27-30]. The diagnostic yield in one study increased from $81.2 \%$ to $90.5 \%$ with an on-site cytologist [27]. ROSE provides a number of benefits that are well documented. It allows needle re-direction and additional sampling in the event of a non-diagnostic aspirate. Conversely, ROSE provides an opportunity to stop sampling when the diagnostic goal is achieved. In some critically ill patients, a preliminary diagnosis at ROSE may be used to guide urgent therapy. Perhaps the most important role of ROSE is its triage function, particularly when managing small amounts of material and multiple required tests [30]. During the bronchoscopy procedure, sample may be obtained in the appropriate amount and placed in the appropriate fixative or other media to ensure adequate material for ancillary testing including molecular testing.

At the Cleveland Clinic, cytopathology professionals involved in the ROSE procedure include cytotechnologists, cytopathology fellows/residents and cytopathologists. An attending cytopathologist is present for all cases. We prepare a maximum of two smears from each needle pass. The remaining material is placed in Cytolyt ${ }^{\mathrm{TM}}$ or RPMI (Roswell Park Memorial Institute medium). One slide from each pair is stained with a modified Romanowsky stain (Hema Diff ${ }^{\mathrm{TM}}$ ) and one slide is fixed in alcohol for Papanicolaou staining. Cell blocks are routinely prepared from all sites (Fig. 3) [31]. Careful attention to smear technique is critical to avoid diagnostic pitfalls related to artifacts. Cytologists and nursing staff receive training on smear preparation from the cytology laboratory. Triage decisions must be made at the time of ROSE. The need for immunohistochemistry and/ or molecular testing is noted and additional material obtained. Gross evaluation of the needle rinse for particles and tissue fragments is stressed as a way to assure an adequate sample. When a preliminary diagnosis of nonsmall cell carcinoma is made at ROSE, in addition to cytologic samples, a needle pass is obtained, placed in formalin and processed in surgical pathology to produce a formalin-fixed, paraffin-embedded tissue block (Fig. 4 and 5). The need for flow cytometry or microbiologic cultures is also assessed at ROSE and material processed accordingly. Of note, we have found one dedicated pass in RPMI for flow cytometry generally yields sufficient lymphoid material (approximately 1 million lymphoid cells) for full flow cytometric immunophenotyping. We view our adequacy assessments in a manner akin to the frozen section, where our interpretation at ROSE further guides the procedure performed. The ROSE procedure has noted disadvantages for the laboratory as it relates to time and reimbursement, which are addressed in the literature [32, 33]. However, most studies show patient benefit with noted decrease in the number of required repeat procedures to obtain diagnostic tissue [28-30]. Further, most studies that highlight the use of cytology samples for molecular testing have an on-site adequacy assessment component [29-31, 34-36]. Importantly, the Centers for Medicare and Medicaid Services (CMS) recently provided clarification related to fine needle aspiration (FNA) and ROSE under CLIA (Clinical Laboratory Improvement Amendments) 1988. Per CMS memo 031618, a slide assessment that provides only a determination of specimen adequacy is not considered to be a slide examination for purposes of determining work load limits in accordance with 42 CFR 493.1274 (d).

There are a number of recent publications that address what constitutes an adequate specimen at ROSE [37-42]. It is generally agreed upon that an adequate specimen for a malignant diagnosis is defined as the presence of sufficient 
Fig. 3 Algorithm for cytology specimen triage at ROSE
Fig. 4 Use of needle rinse samples for morphologic evaluation, immunohistochemistry and molecular testing

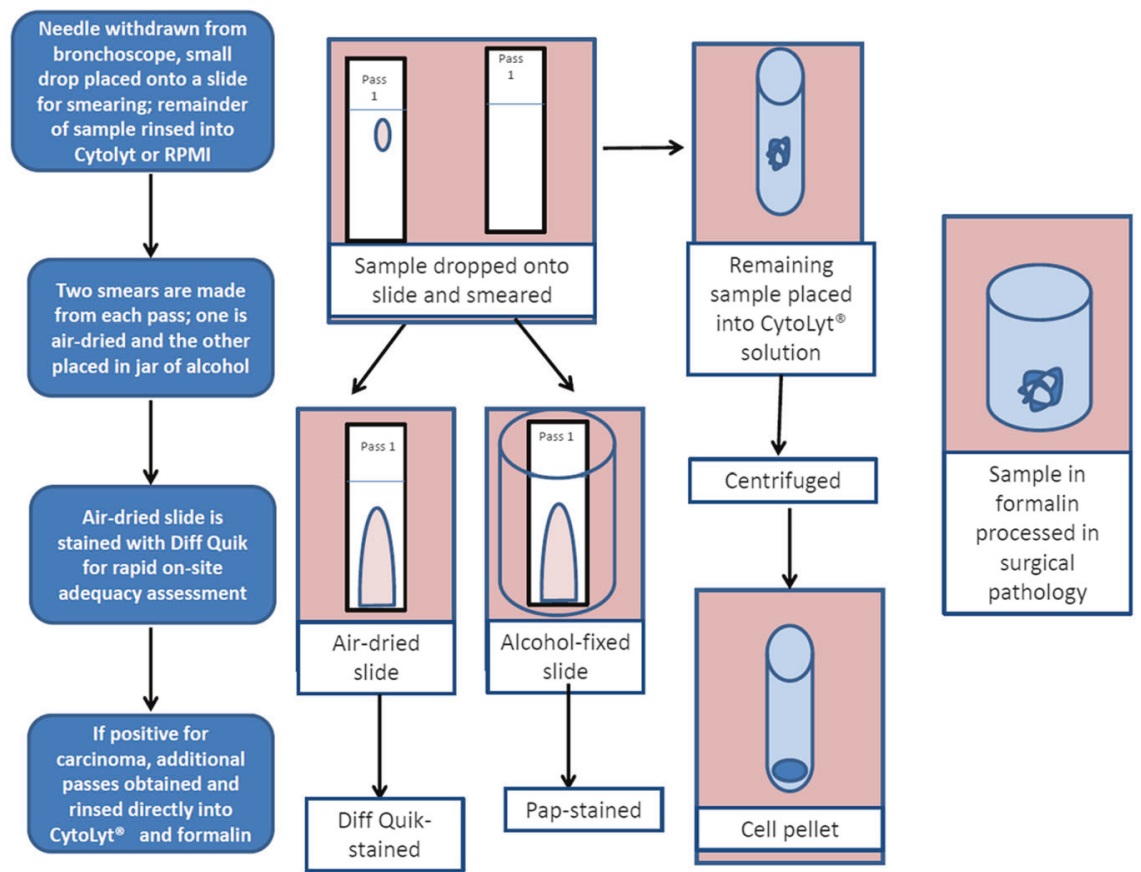

Modified from Doxtader E, Cheng YW and Zhang Y. Arch Pathol Lab Med 2018 epub ahead of print

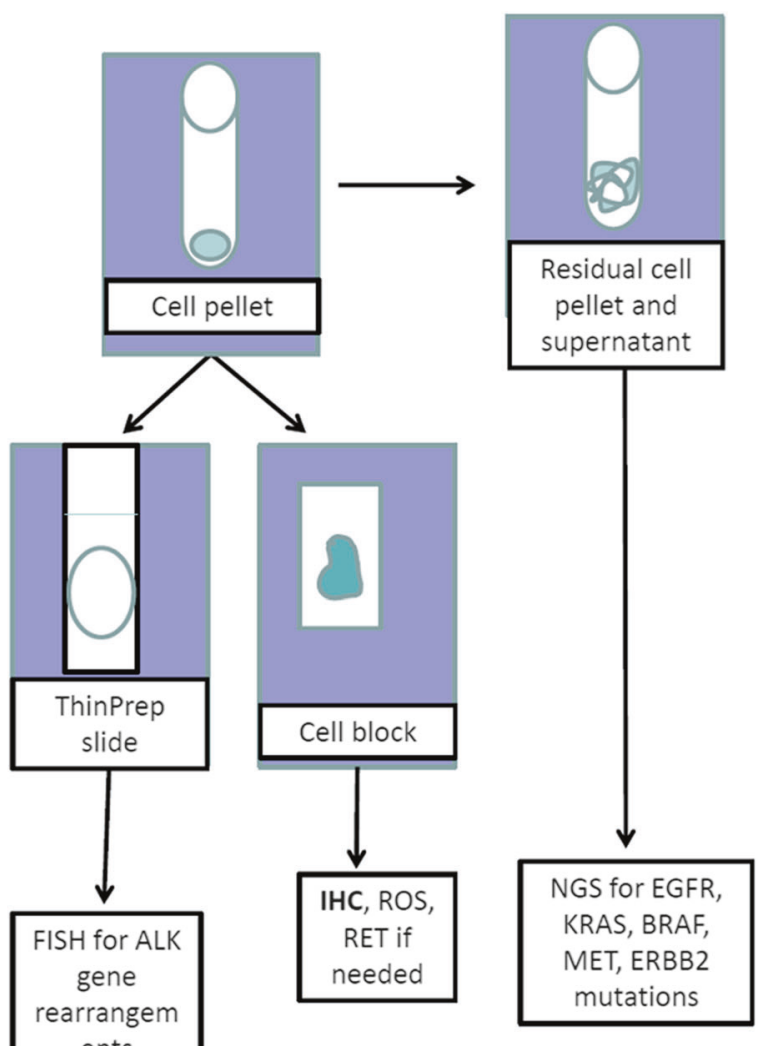

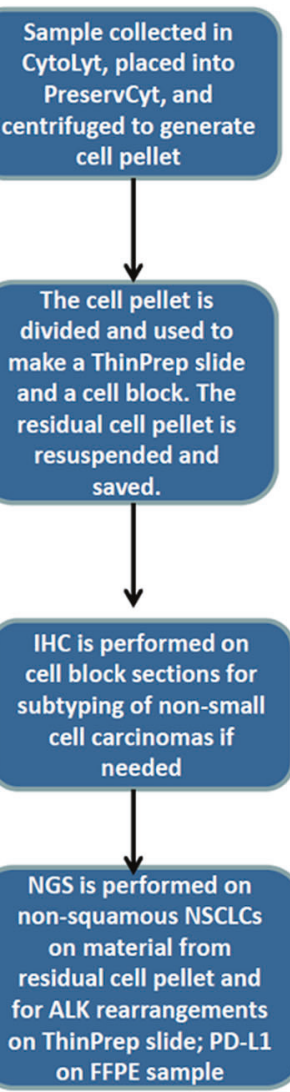

Sample collected in

Cytolyt, placed into

centrifuged to generate cell pellet

Modified from Doxtader E, Cheng YW and Zhang Y. Arch Pathol Lab Med 2018 epub ahead of print

material for morphologic diagnosis and ancillary testing for cell typing, treatment and prognosis. A multidisciplinary approach to define what is needed for "positive" cases is required. At our institution, discussions take place between 
Table 6 Adequacy criteria for lymph node sampling

\begin{tabular}{ll}
\hline Author & Criteria \\
\hline Choi et al. [42] & $\begin{array}{l}\text { Tissue core size }(\geq 2 \mathrm{~cm}) \text {, anthracotic pigment, increased lymphocyte density } \\
(\geq 40 \text { lymphocytes/hpf, mean 10 fields })\end{array}$ \\
$\begin{array}{l}\text { Nayak et al. [41] (New } \\
\text { Over 5 low-power fields with at least 100 lymphocytes and less than 2 groups } \\
\text { of bronchial cells per low-power field OR germinal center fragments }\end{array}$ \\
$\begin{array}{l}\text { Feller-Kopman et al. [40] } \\
\text { Mlsharif et al. [39] }\end{array}$ & $\begin{array}{l}>40 \text { Lymphocytes per high-magnification field or clusters of pigment-laden } \\
\text { macrophages }\end{array}$ \\
Patelli et al. [38] & Lymphocytes compose at least 30\% of cellularity \\
\hline
\end{tabular}

Formalin-

fixed samples

include TBBX, EBBX or

FNA/core

from lymph

node

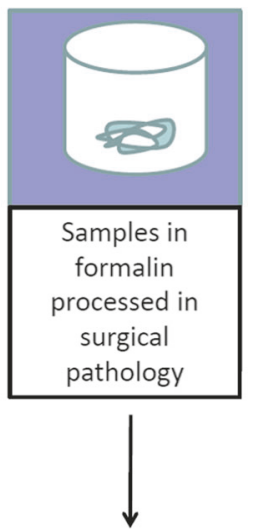

\section{IHC, PD-L1, ROS, RET, \\ NGS if \\ needed}

Modified from Doxtader E, Cheng YW and Zhang Y. Arch Pathol Lab Med 2018 epub ahead of print

Fig. 5 Use of paraffin-embedded formalin fixed FNA samples processed in surgical pathology

colleagues in pathology (cytopathology, pulmonary surgical pathology and molecular pathology subspecialties), interventional pulmonology and oncology to decide our approach to sampling and ancillary testing. The pulmonologists defined the most reasonable number of needle passes that could be safely obtained to meet current testing needs, as defined by our oncologists. We correlated that with expected DNA yields. The pathologists in the group determined how our subspecialties would work together to optimize tissue handling and logistics. We additionally meet when needed to discuss our results and/or alter our approach in the face of new testing requirements. Testing algorithms change regularly in this rapidly evolving field, and hence an approach that fosters easy communication and team work is needed to implement changes as they arise.

Adequacy criteria for a benign lymph node sample vary in the literature with no agreed upon standard. Some of the proposed criteria are summarized in Table 6 [37-42]. We have found the use of criteria requiring lymphoid cell counts difficult to apply in the fast-paced environment of the bronchoscopy suites. We use a rapid assessment of overall lymphoid cellularity to determine specimen adequacy. We reviewed our experience in 174 patients who underwent staging EBUS-FNA prior to tumor resection [43]. In these patients, 330 of 578 lymph nodes sampled at EBUS were resected. There was concordance between the cytology and histology in 311 of 330 lymph nodes (94\%), with discrepancies related to sampling error in all cases. The majority of the discrepant cases (83\%) had adequate lymphoid samples that met all published criteria available during the study period. However, a significant minority, $17 \%$ did not meet criteria for adequacy. Many of these lymphoid samples were interpreted as "limited lymphoid sample" at ROSE, terminology that is best avoided. Of note, in 10 of the discrepant lymph nodes, the metastatic deposit in the surgical pathology specimen measured less than $2 \mathrm{~mm}$.

Once a cellular diagnostic sample from a non-small cell carcinoma is obtained, attention is turned to appropriate processing for molecular testing. At our institution, use of cytology samples for certain molecular tests is prioritized. Our approach to molecular testing in cytology samples and small biopsies is summarized in Figs. 4 and 5 [31]. In all cases, specimen cellularity is assessed and recorded using the ThinPrep slide before material is submitted to molecular pathology.

\section{Next-generation sequencing (NGS)}

The needle rinse sample is collected in Cytolyt ${ }^{\mathrm{TM}}$ and centrifuged to form a cell pellet. The cell pellet is divided and used to make a ThinPrep slide and a Cellient ${ }^{\mathrm{TM}}$ cell block. The residual cell pellet, comprising the majority of the pellet together with the supernatant (containing cell free DNA), is submitted to molecular pathology for DNA extraction and NGS [44]. If immunohistochemical stains are needed for cell typing of the non-small cell carcinoma, they are performed on the cell block. In this way, tissue needs for NGS do not compete with cell block material for immunohistochemistry (IHC). A 50-gene NGS hotspot panel is utilized and has 
Fig. 6 Schematic representation of ALK/EML4 translocation by FISH and immunohistochemistry. Image provided by Eugen $\mathrm{C}$ Minca, MD PhD

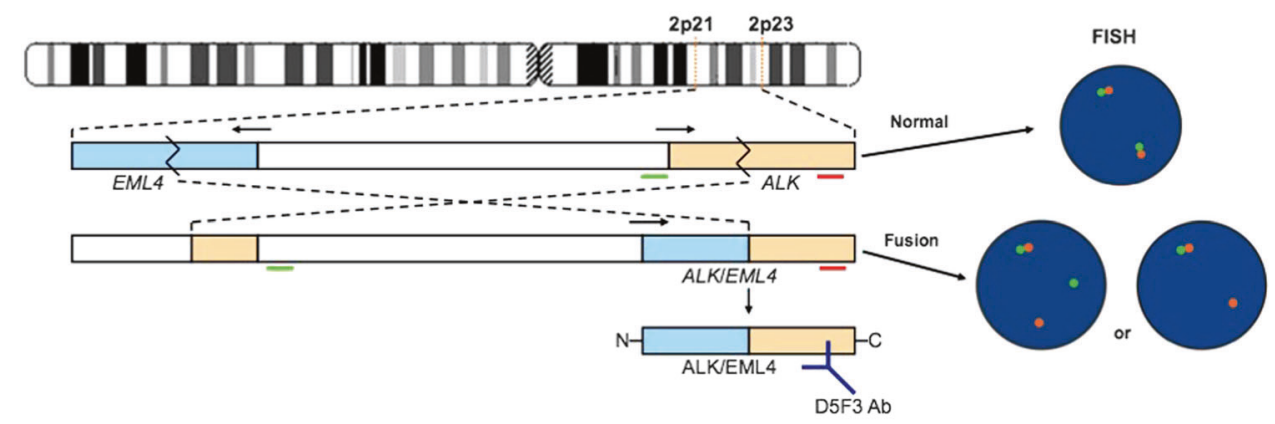

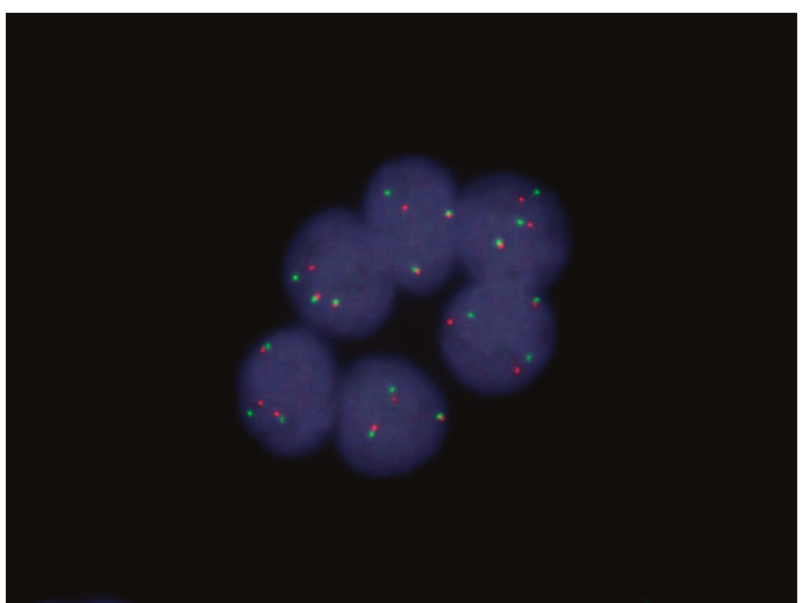

Fig. 7 Positive FISH for ALK/EML4 translocation performed on a ThinPrep slide

been validated on cytology samples [44]. Results of NGS for 5 genes are currently reported including: $E G F R, K R A S$, BRAF, ERBB2 and MET. In 2016 and 2017, adequate samples were obtained for NGS $98-99 \%$ of the time for all specimen types, including outside consultation material. In 2017, two cytology cases $(0.55 \%)$ called adequate at ROSE were not adequate for NGS based on DNA yield requirements. Importantly, an alternate sample in both of these cases was available for testing.

\section{ALK gene rearrangements}

In most cases, the same ThinPrep slide used in part for morphologic diagnosis is submitted to molecular pathology for fluorescence in situ hybridization (FISH) for the detection of $A L K$ gene rearrangements according to previously published methods [45]. Use of the ThinPrep slide essentially guarantees that sufficient tumor is present for interpretation of the $A L K$ FISH. Fifty evaluable tumor cells is the cellularity requirement for testing. In 2017, we had a 5\% positivity rate for an $A L K$ gene rearrangement. The majority of testing was performed on the ThinPrep from cytology

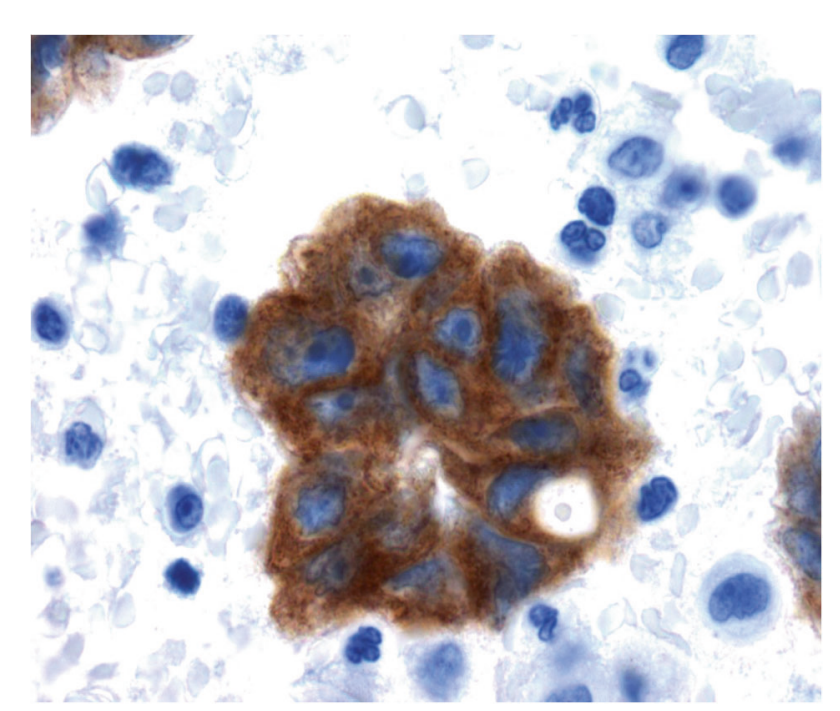

Fig. 8 Positive immunohistochemical stain for ALK (D5F3 clone)

samples and all cases were adequate for evaluation by FISH. Commercial break apart FISH probes consist of red and green probes that flank the highly conserved translocation break point within the $A L K$ gene (Fig. 6) [45]. In normal cells the probes are close together and produce a fused yellow signal. In tumor cells harboring $A L K$ rearrangements, the probes are split and show red and green probes at a distance from one another. Fifty tumor cell nuclei are scored. A case is positive when $15 \%$ of tumor cells demonstrate isolated red and green signals or red signals (Fig. 7). Alternatively, immunohistochemistry for $A L K$ gene rearrangements may be performed. Ultrasensitive $A L K$ IHC using the rabbit monoclonal antibody D5F3 detects the aberrant ALK protein that results from this gene rearrangement (Fig. 8).

\section{ROS1 and RET gene rearrangements}

Formalin-fixed, paraffin-embedded tissue samples are used to analyze non-small cell carcinomas for ROSI and RET gene rearrangements at our institution by FISH. This procedure is 


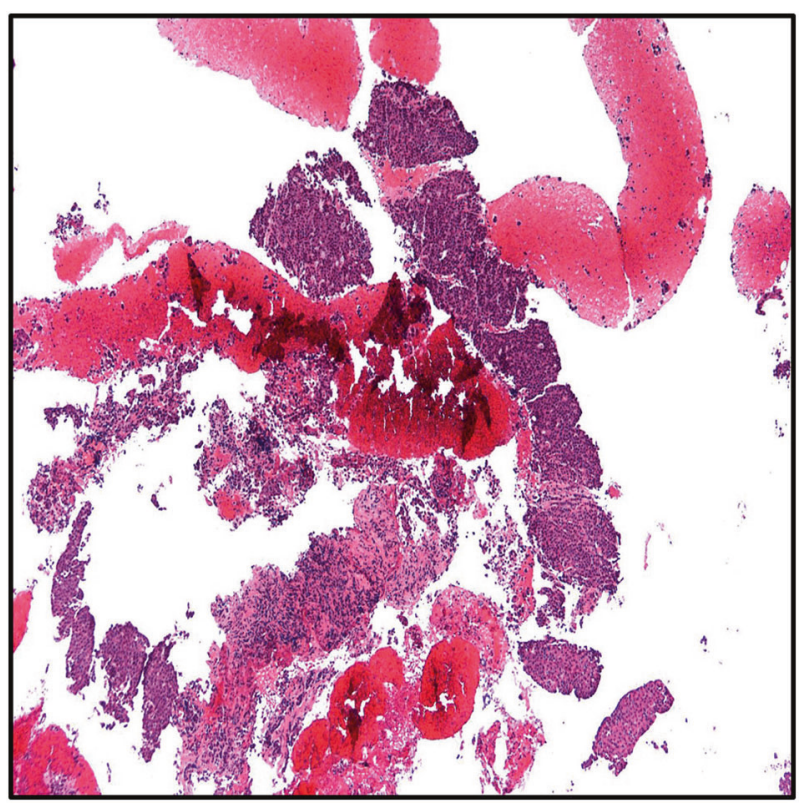

Fig. 9 Lymph node FNA sample fixed in formalin

also internally validated for cytology cell blocks fixed in methanol-based fixative (Cytolyt ${ }^{\mathrm{TM}}$ ). The FISH probes work in an analogous way to the $A L K$ FISH discussed above, where probes hybridize to sequences adjacent to either ROS1 or RET to detect rearrangements of these genes with multiple fusion partners [46]. Positive FISH results for these rearrangements also result in separate red and green signals.

\section{PD-L1 immunohistochemistry}

PD-L1 is expressed on tumor cells and immune cells which likely helps tumors escape cytotoxic $\mathrm{T}$ cells [47]. The greater the degree of expression of PD-L1 on tumor cells, the more likely that tumor will respond to immunotherapy. Targeted chemotherapy drugs may inhibit PD-L1 and enable activation of cytotoxic $\mathrm{T}$ cells to kill tumor cells. We test all nonsmall cell carcinomas for PD-L1 using an internally validated assay and the 22C 3 antibody. We use formalin-fixed, paraffin-embedded biopsy or cytology material for this testing (Fig. 9). PD-L1 grading in lung cancer is a threetiered system. A positive result is any membranous staining of greater than $1 \%$ of tumor cells. Positive cases are further divided into less than or greater than $50 \%$ of tumor cells staining. A positive case with greater than $50 \%$ tumor cell positivity is illustrated in Fig. 10.

\section{Practical tips}

Through trial and error, we have found some aspects of our process helpful in ensuring that we have enough

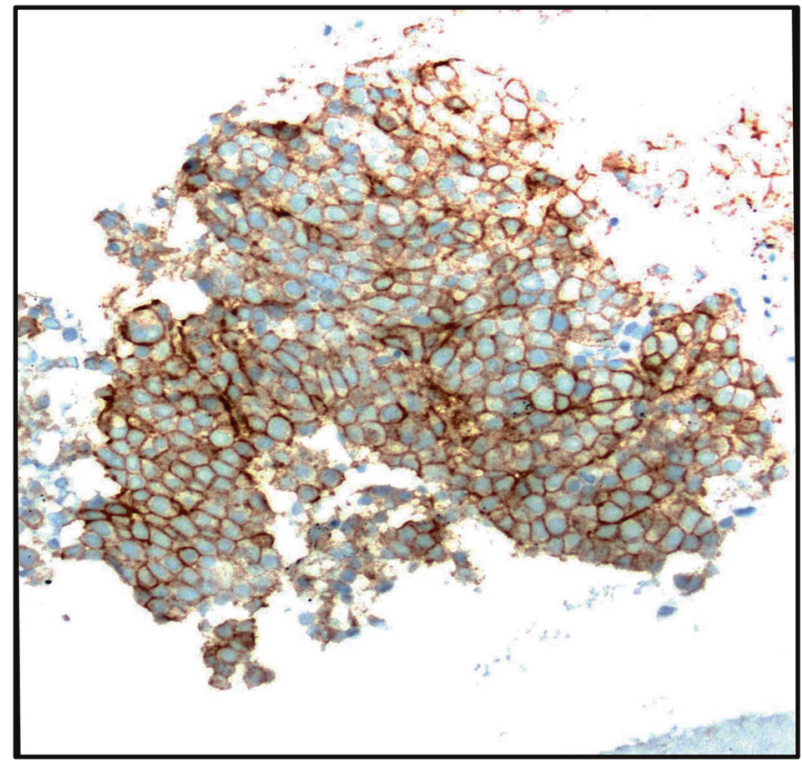

Fig. 10 Immunohistochemical stain for PD-L1 performed on the formalin-fixed lymph node sample depicted in Fig. 9

sample for molecular testing and that the appropriate testing is performed. First, attention to triage and the gross appearance of the needle rinse sample during the ROSE procedure cannot be over-emphasized. We also have unified our approach to ordering molecular tests that include an assessment of specimen cellularity. Our molecular technologists have rotated in Cytology to understand our process and vice versa. This has served to foster ongoing real-time communication between our laboratories. We have regularly scheduled meetings involving cytology, pulmonary surgical pathology and molecular pathology to work on the logistics of our process and optimize turnaround time. We have also added two Molecular Coordinator positions. Individuals in these clerical positions make sure that the appropriate testing is ordered on all patients, interface with clinicians for specific requests and perform a troubleshooting function for all molecular testing in Anatomic Pathology, including lung cancer molecular testing.

\section{Summary}

In summary, targeted therapies for lung cancer have proven effective and continue to evolve. Immunohistochemical studies performed in a tissue-sparing manner to define the cell type of a non-small cell carcinoma are essential. Tissue utilization for molecular testing on small samples must be optimized using biopsy and cytology specimens. This requires attention to the details of the process and close communication across disciplines. 


\section{Compliance with ethical standards}

Conflict of interest The authors declare that they have no conflict of interest.

\section{References}

1. Siegel R, Naishadham D, Jemal A. Cancer statisitcs, 2013. CA Cancer J Clin. 2013;63:11-20.

2. Vachani A, Sequist LV, Spira A. The shifting landscape for lung cancer: past, present, and future. Am J Respir Crit Care Med. 2017;195:1150-60.

3. Aberle DR, Berg CD, Adams AM. et al. Reduced lung-cancer mortality with low-dose computed tomographic screen. N Engl J Med. 2011;365:395-409.

4. Socinski MA, Evans T, Gettinger S. Treatment of stage IV nonsmall cell lung cancer: diagnosis and management of lung cancer, 3rd ed: American College of Chest Physicians evidence-based clinical practice guidelines. Chest. 2013;143:e341S-68.

5. Lindeman NI, Cagle PT, Aisner DL, et al. Updated molecular testing guideline for the selection of lung cancer patients for treatment with targeted tyrosine kinase inhibitors: guideline from the College of American Pathologists, the International Association for the Study of Lung Cancer, and the Association for Molecular Pathology. Thorac Oncol. 2018;13:323-58.

6. Paez JG, Jänne PA, Lee JC, et al. EGFR mutations in lung cancer: correlation with clinical response to gefitinib therapy. Science. 2004;304:1497-500.

7. Pao W, Miller VA. Epidermal growth factor receptor mutations, small-molecule kinase inhibitors, and non-small-cell lung cancer: current knowledge and future directions. J Clin Oncol. 2005;23:2556-68.

8. Lynch TJ, Bell DW, Sordella R, et al. Activating mutations in the epidermal growth factor receptor underlying responsiveness of non-small-cell lung cancer to gefitinib. $\mathrm{N}$ Engl $\mathrm{J}$ Med. 2004;350:2129-39.

9. Kwak EL, Bang YJ, Camidge DR, et al. Anaplastic lymphoma kinase inhibition in non-small-cell lung cancer. N Engl J Med. 2010;363:1693-703.

10. Soda M, Choi YL, Enomoto M, et al. Identification of the transforming EML4-ALK fusion gene in non-small-cell lung cancer. Nature. 2007;448:561-6.

11. Hirsch FR, Suda K, Wiens J, et al. New and emerging targeted treatments in advanced non-small-cell lung cancer. Lancet. 2016;388:1012-24.

12. Lindeman NI, Cagle PT, Beasley MB, et al. Molecular testing guideline for selection of lung cancer patients for EGFR and ALK tyrosine kinase inhibitors: guideline from the College of American Pathologists, International Association for the Study of Lung Cancer, and Association for Molecular Pathology. J Thorac Oncol. 2013;8:823-59; erratum: 8, 134 (2013).

13. Pirker R, Herth FJ, Kerr KM, et al. Consensus for EGFR mutation testing in non-small cell lung cancer: results from a European workshop. J Thorac Oncol. 2010;5:1706-13.

14. Leighl NB, Rekhtman N, Biermann WA, et al. Molecular testing for selection of patients with lung cancer for epidermal growth factor receptor and anaplastic lymphoma kinase tyrosine kinase inhibitors: American Society of Clinical Oncology endorsement of the College of American Pathologists/International Association for the study of lung cancer/association for molecular pathology guideline. J Clin Oncol. 2014;32:3673-9.

15. Lindeman NI, Cagle PT, Aisner DL, et al. Updated molecular testing guideline for the selection of lung cancer patients for treatment with targeted tyrosine kinase inhibitors: guideline from the College of American Pathologists, the International Association for the Study of Lung Cancer, and the Association for Molecular Pathology. Arch Pathol Lab Med. 2018;142:321-46.

16. Lindeman NI, Cagle PT, Aisner DL, et al. Updated Molecular Testing Guideline for the Selection of Lung Cancer Patients for Treatment with Targeted Tyrosine Kinase Inhibitors: Guideline From the College of American Pathologists, the International Association for the Study of Lung Cancer, and the Association for Molecular Pathology. J Mol Diagn. 2018;2:129-59.

17. Zachara-Szczakowski S, Tyler Verdun MD, Andrew Churg MD. Accuracy of classifying poorly differentiated non-small cell lung carcinoma biopsies with commonly used lung carcinoma markers. Hum Pathol. 2015;46:776-82.

18. Kadota K, Nitadori J, Rekhtman N, et al. Reevaluation and reclassification of resected lung carcinomas originally diagnosed as squamous cell carcinoma using immunohistochemical analysis. Am J Surg Pathol. 2015;39:1170-80.

19. Mukhopadhyay S, Katzenstein ALA. Subclassification of nonsmall cell lung carcinoma lacking morphologic differentiation on biopsy specimens: utility of an immunohistochemical panel containing TTF-1, napsin A, p63, and CK5/6. Am J Surg Pathol. 2011;35:15-25.

20. Travis WD, Brambilla E, Noguchi M, et al. International Association for the Study of Lung Cancer/American Thoracic Society/ European Respiratory Society international multidisciplinary classification of lung adenocarcinoma. $\mathbf{J}$ Thorac Oncol. 2011;6:244-85.

21. Pelosi G, Scarpa A, Forest F, et al. The impact of immunohistochemistry on the classification of lung tumors. Expert Rev Respir Med. 2016;10:1105-21.

22. Julien PL, Vincentena Egbert F, Smitb KG, et al. Is the current diagnostic algorithm reliable for selecting cases for EGFR- and KRAS-mutation analysis in lung cancer? Lung Cancer. 2015;89:19-26.

23. Vincenten JP, Smit EF, Grünberg K, et al. Is the current diagnostic algorithm reliable for selecting cases for EGFR- and KRASmutation analysis in lung cancer? Lung Cancer. 2015;89:19-26.

24. Chaft JE, Rekhtman N, Ladanyi M, et al. ALK-rearranged lung cancer: adenosquamous lung cancer masquerading as pure squamous carcinoma. J Thorac Oncol. 2012;7:768-9.

25. Rekhtman N, Paik PK, Arcila ME, et al. Clarifying the spectrum of drive oncogene mutations in biomarkers verified squamous carcinoma of lung: lack of EGFR/KRAS and presence of PIK3CA/AKT1 mutations. Clin Cancer Res. 2012;15:1167-76.

26. Mullon JJ, Burkart KM, Silvestri G, et al. Interventional pulmonology fellowship accreditation standards. Chest. 2017;151:1-8.

27. Guo H, Liu S, Guo G, et al. Rapid on-site evaluation during endobronchial ultrasound-guided transbronchial needle aspiration for the diagnosis of hilar and mediastinal lymphadenopathy in patients with lung cancer. Cancer Lett. 2016;371:182-6.

28. Collins BT, Chen AC, Wang JF, et al. Improved laboratory resource utilization and patient care with the use of rapid on-site evaluation for endobronchial ultrasound fine-needle aspiration biopsy. Cancer Cytopathol. 2013;121:544-51.

29. Trisolini R, Cancellieri A, Tinelli C, et al. Randomized trial of endobronchial ultrasound-guided transbronchial needle aspiration with and without rapid on-site evaluation for lung cancer genotyping. Chest. 2015;148:1430-7.

30. Jain D, Allen TC, Aisner DL, et al. Rapid on-site evaluation of endobronchial ultrasound-guided transbronchial needle aspirations for the diagnosis of lung cancer: a perspective from members of the pulmonary pathology society. Arch Pathol Lab Med. 2018;142:252-62.

31. Doxtader EE, Cheng YW, Zhang Y. Molecular testing of nonsmall cell lung carcinoma diagnosed by endobronchial ultrasound- 
guided transbronchial fine-needle aspiration. Arch Pathol Lab Med 2018. https://doi.org/10.5858/arpa.2017-0184-RA

32. Layfield LJ, Bentz JS, Gopez EV. Immediate on-site interpretation of fine needle aspiration smears: a cost and compensation analysis. Cancer. 2001;93:319-22.

33. Eades CR, Wang HH. Cost effectiveness of immediate specimen adequacy assessment of thyroid fine-needle aspirations. Am J Clin Pathol. 2004;121:64-9.

34. Sung S, Crapanzano JP, DiBardino D, et al. Molecular testing on endobronchial ultrasound (EBUS) fine needle aspirates (FNA): impact of triage. Diagn Cytopathol. 2018;46:122-30.

35. Stevenson T, Powari M, Bowles C. Evolution of a rapid onsite evaluation (ROSE) service for endobronchial ultrasound guided (EBUS) fine needle aspiration (FNA) cytology in a UK hospital: a 7 year audit. Diagn Cytopathol. 2018;46:656-62.

36. Roy-Chowdhuri S, Aisner DL, Allen TC, et al. Biomarker testing in lung carcinoma cytology specimens: a perspective from members of the pulmonary pathology society. Arch Pathol Lab Med. 2016;140:1267-72.

37. Baker JJ, Solanki PH, Schenk DA, et al. Transbronchial fine needle aspiration of the mediastinum: importance of lymphocytes as an indicator of specimen adequacy. Acta Cytol. 1990;34:517-23.

38. Patelli M, Lazzari AL, Poletti V, et al. Role of fiberoptic transbronchial needle aspiration in the staging of $\mathrm{N} 2$ disease due to non-small cell lung cancer. Ann Thorac Surg. 2002;73:407-11.

39. Alsharif M, Andrade RS, Groth SS, et al. Endobronchial ultrasound-guided transbronchial fine-needle aspiration: the University of Minnesota experience, with emphasis on usefulness, adequacy assessment, and diagnostic difficulties. Am J Clin Pathol. 2008;130:434-43.

40. Feller-Kopman D, Yung RC-W, Burroughs F, et al. Cytology of endobronchial ultrasound-guided transbronchial needle aspiration: a retrospective study with histology correlation. Cancer Cytopathol. 2009;117:482-90.

41. Nayak A, Sugrue C, Koenig S, et al. Endobronchial ultrasoundguided transbronchial needle aspirate (EBUS-TBNA): a proposal for on-site adequacy criteria. Diagn Cytopathol. 2012;40:128-37.

42. Choi SM, Lee AR, Choe JY, et al. Adequacy criteria of rapid onsite evaluation for endobronchial ultrasound-guided transbronchial needle aspiration: a simple algorithm to assess the adequacy of ROSE. Ann Thorac Surg. 2016;101:444-50.

43. Kobalka P, Zhang Y, Brainard J. Endobronchial ultrasoundguided fine needle aspiration (EBUS-FNA): a cytologic-histologic correlation with emphasis on discordant cases. Mod Pathol. 2017;30:102A.

44. Reynolds JP, Zhou Y, Jakubowski MA, et al. Next-generation sequencing of liquid-based cytology non-small cell lung cancer samples. Cancer Cytopathol. 2017;125:178-87.

45. Minca EC, Lanigan CP, Reynolds JP, et al. $A L K$ status testing in non-small cell lung carcinoma by FISH on ThinPrep slides with cytology material. J Thorac Oncol. 2014;9:464-8.

46. Gainor JF, Shaw AT. Novel targets in non-small cell lung cancer: ROS1 and RET fusions. Oncologist. 2013;18:865-75.

47. Sholl LM, Aisner DL, Allen TC, et al. Programmed death ligand-1 immunohistochemistry- a new challenge for pathologists: a perspective from members of the pulmonary pathology society. Arch Pathol Lab Med. 2016;140:341-4. 